\title{
EnRoot: a narrow-diameter, inexpensive and partially 3D-printable minirhizotron for imaging fine root production
}

\author{
Marie Arnaud ${ }^{1 *} \mathbb{O}$, Andy J. Baird ${ }^{1}$, Paul J. Morris ${ }^{1}$, Angela Harris ${ }^{2}$ and Jonny J. Huck ${ }^{2}$
}

\begin{abstract}
Background: Fine root production is one of the least well understood components of the carbon cycle in terrestrial ecosystems. Minirhizotrons allow accurate and non-destructive sampling of fine root production. Small and large scale studies across a range of ecosystems are needed to have baseline data on fine root production and further assess the impact of global change upon it; however, the expense and the low adaptability of minirhizotrons prevent such data collection, in worldwide distributed sampling schemes, in low-income countries and in some ecosystems (e.g. tropical forested wetlands).

Results: We present EnRoot, a narrow minirhizotron of $25 \mathrm{~mm}$ diameter, that is partially 3D printable. EnRoot is inexpensive $(€ 150)$, easy to construct (no prior knowledge required) and adapted to a range of ecosystems including tropical forested wetlands (e.g. mangroves, peatlands). We tested EnRoot's accuracy and precision for measuring fine root length and diameter, and it yielded Lin's concordance correlation coefficient values of 0.95 for root diameter and 0.92 for length. As a proof of concept, we tested EnRoot in a mesocosm study, and in the field in a tropical mangrove. EnRoot proved its capacity to capture the development of roots of a legume (Medicago sativa) and a mangrove species (seedlings of Rhizophora mangle) in laboratory mesocosms. EnRoot's field installation was possible in the rootdense tropical mangrove because its narrow diameter allowed it to be installed between larger roots and because it is fully waterproof. EnRoot compares favourably with commercial minirhizotrons, and can image roots as small as $56 \mu \mathrm{m}$.

Conclusion: EnRoot removes barriers to the extensive use of minirhizotrons by being low-cost, easy to construct and adapted to a wide range of ecosystem. It opens the doors to worldwide distributed minirhizotron studies across an extended range of ecosystems with the potential to fill knowledge gaps surrounding fine root production.
\end{abstract}

Keywords: Minirhizotron, Root production, Belowground carbon, Fine roots, 3D minirhizotron, Root monitoring, Belowground biomass, Carbon sequestration, Root dynamics

\section{Background}

Root production is one of the least studied components of terrestrial ecosystems, despite being likely to represent a third of net primary production [6]. Several techniques exist to measure in situ fine root production, but quantifying such subterranean processes remains difficult and often expensive. Minirhizotrons involve the installation of a transparent tube into the soil, into which a camera is inserted periodically to record root development [5].

\footnotetext{
*Correspondence: gymasa@leeds.ac.uk; m.arnaudd@gmail.com ${ }^{1}$ School of Geography, University of Leeds, Leeds LS2 9JT, UK Full list of author information is available at the end of the article
}

Net root production is estimated by calculating changes in root diameters and lengths between successive images [7].

Minirhizotrons have proven to be accurate for root production measurements [7] and overcome limitations associated with other methods because: (i) the same roots and soil profile are sampled repeatedly, reducing the spatial component of experimental error [4]; (ii) root production and mortality are measured simultaneously, minimising the likelihood of missing any roots with a fast turnover (appearance, growth and death, [3]); (iii) they do not use artificial soil substrate, which might modify the

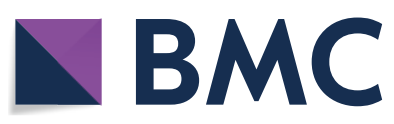

(c) The Author(s) 2019. This article is distributed under the terms of the Creative Commons Attribution 4.0 International License (http://creativecommons.org/licenses/by/4.0/), which permits unrestricted use, distribution, and reproduction in any medium, provided you give appropriate credit to the original author(s) and the source, provide a link to the Creative Commons license, and indicate if changes were made. The Creative Commons Public Domain Dedication waiver (http://creativecommons.org/ publicdomain/zero/1.0/) applies to the data made available in this article, unless otherwise stated. 
root production unlike ingrowth cores [13]; and (iv) they are non-destructive; once the minirhizotron tubes have been installed, no subsequent disturbance is required to take repeated measurements [9]. The minimal disturbance is advantageous for both mesocosm studies and long-term field experiments.

Minirhizotrons do, however, have limitations. They are expensive [12] and lack a standardised design; consequently, they are not used in worldwide distributed sampling schemes, such as RAINFOR and GEM networks plots [10] and are rarely used in low-income countries. Additionally, they are not well adapted to wetland conditions [5], including tropical forested wetlands. While working in waterlogged wetland soils or during heavy rain (e.g. monsoon), commercial minirhizotron cameras, being non-waterproof, can be easily damaged. Large above- and below-ground roots, also make the installation of commercially-available minirhizotron tubes (with diameters of over $50 \mathrm{~mm}$ ) in tropical forested wetlands difficult or impossible. As a result, minirhizotrons are either not used (e.g., in mangroves) or are located away from tree trunks, resulting in potentially unrepresentative fine root production estimates. Narrow minirhizotrons would be easier to install. Hand-made minirhizotrons might partially overcome the price limitation, but are usually produced in small numbers for a specific application, are hard to construct (prior knowledge is required), and often are not well documented. There is a need for a minirhizotron that overcomes the limitations identified above and that can be made cheaply and easily to a reproducible specification that allows comparison among and between sites and ecosystems.

Here, we report the development and testing of a narrow, waterproof and inexpensive minirhizotron that can be repeatedly and easily made to a standardised specification: EnRoot. With its narrow diameter and waterproof camera, EnRoot is easy to install and suitable for a large range of ecosystems, including tropical forested wetlands. The material costs-including the camera-are less than $€ 150$ per unit. EnRoot is easy to assemble and to reproduce to a standard with its 3D printable components costing less than $€ 35$, and has similar imaging capabilities to commercial minirhizotrons.

\section{Results and discussion}

The new minirhizotron system: EnRoot

Description and set up of EnRoot

EnRoot has two main components-an imaging module and a soil tube (Figs. 1, 2). Both are very narrow; the module has an outside diameter of $25 \mathrm{~mm}$, and the soil

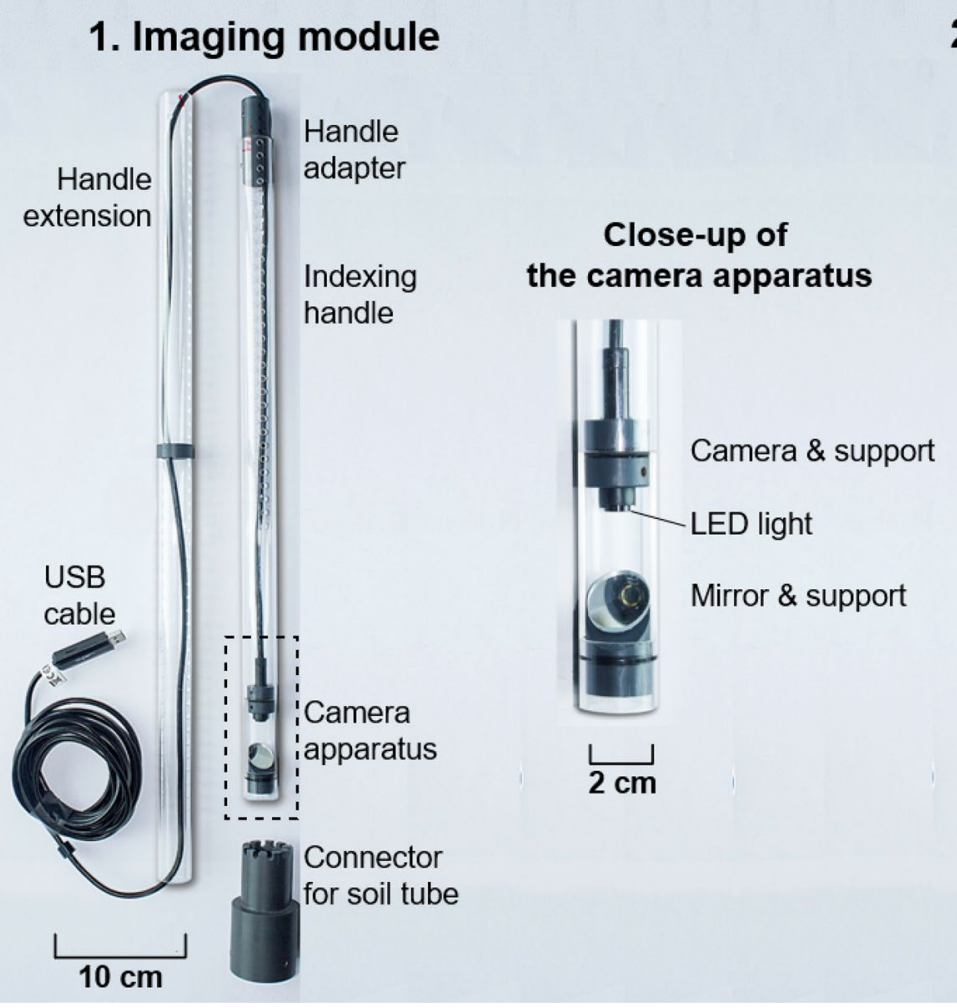

2. Soil tube

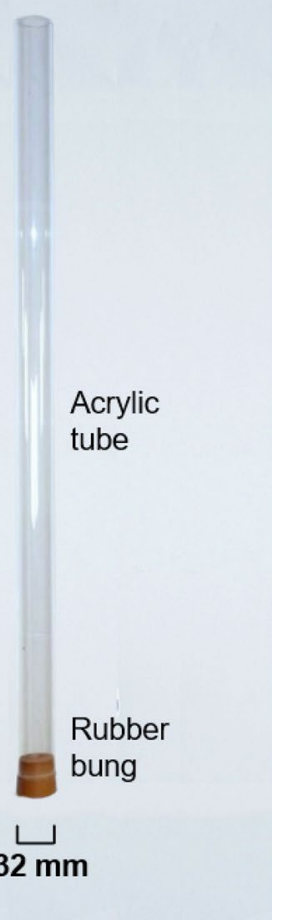

Fig. 1 EnRoot's components. All the grey plastic components are 3D printable 


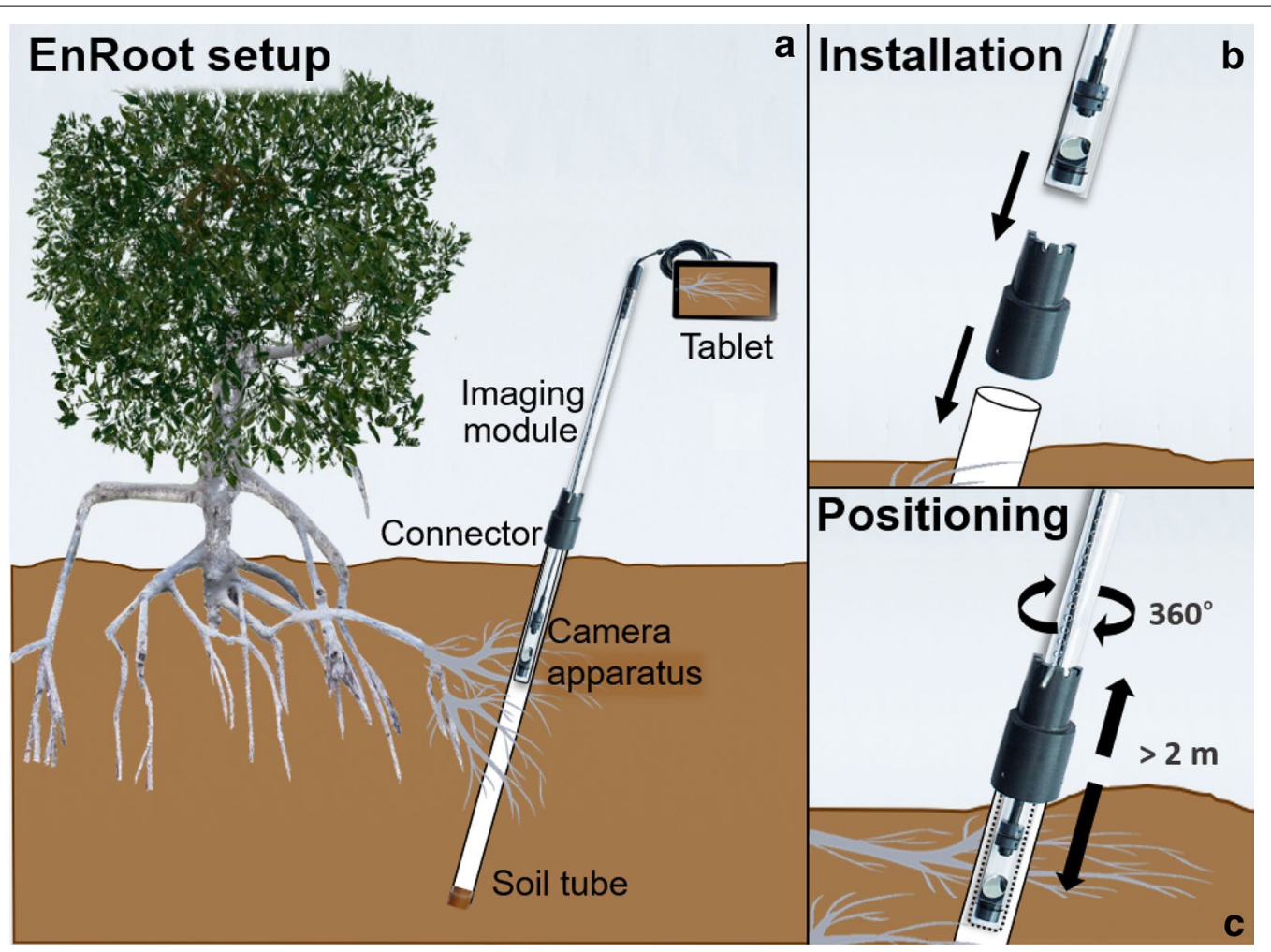

Fig. 2 EnRoot's setup and usage

tube an outside diameter of $32 \mathrm{~mm}$. EnRoot's soil tube is left permanently buried in the soil to allow the development of roots around it (Fig. 2a). The tube is made from clear acrylic ( $2 \mathrm{~mm}$ thick; purchased from http://thepl asticshop.co.uk) and has a rubber bung fitted in its base (Fig. 1). The imaging module is composed of an indexing handle and a camera apparatus (Fig. 1); both have and inside diameter of $21 \mathrm{~mm}$, and an outside diameter of $25 \mathrm{~mm}$. The camera apparatus is $15 \mathrm{~cm}$ long and the indexing handle $45 \mathrm{~cm}$ long. The handle extension length is adjustable so that the camera apparatus can reach the bottom of soil tubes. The holes of the indexing handle and its extension are drilled every centimetre with a pillar drill (AJVBM 4, Ajax) using a drill bit of $4 \mathrm{~mm}$. The distance between the drilled holes can be adjusted to take pictures with no or a range of overlaps. The camera apparatus has a window through which the roots are directly observed with a camera (Potensic ${ }^{\circledR} 2$-in-1 USB Endoscope with LEDs) and a mirror orientated at $40^{\circ}$ relative to the soil tube's long axis (Fig. 3).

The imaging module is inserted into the soil tube, and the full circumference and length of the tube (around where the roots are developing) is imaged by incrementally rotating and moving up and down the imaging module within the soil tube (Figs. 2c, 4). The position of the

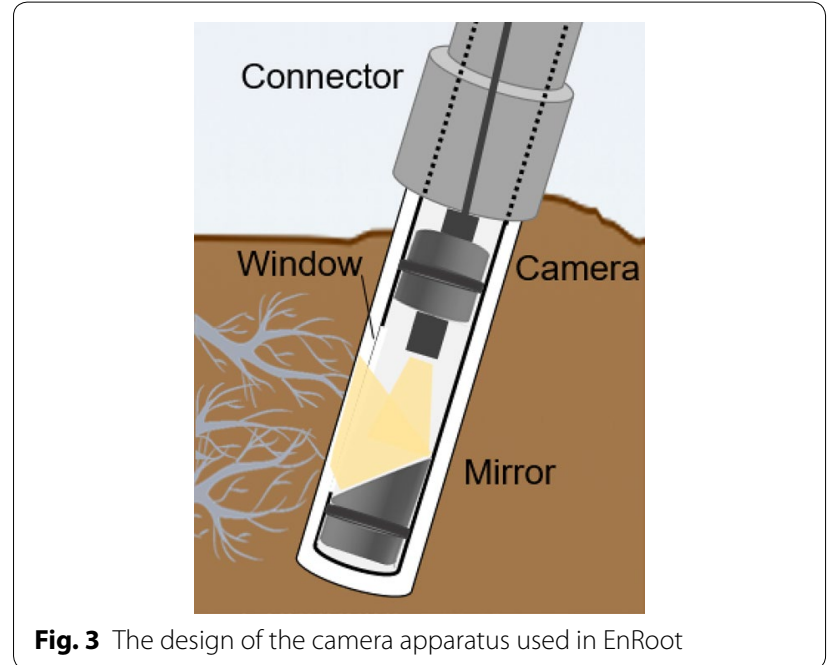

imaging system can be recorded by inserting a metal rod at a known position into (i) the connector castellated every $5 \mathrm{~mm}$ for a $360^{\circ}$ coverage, and (ii) the indexing handle perforated every centimetre to reach any depth in the soil tube (Fig. 4). The record of the position allows repeated measurements of the same roots and soil area over time. 


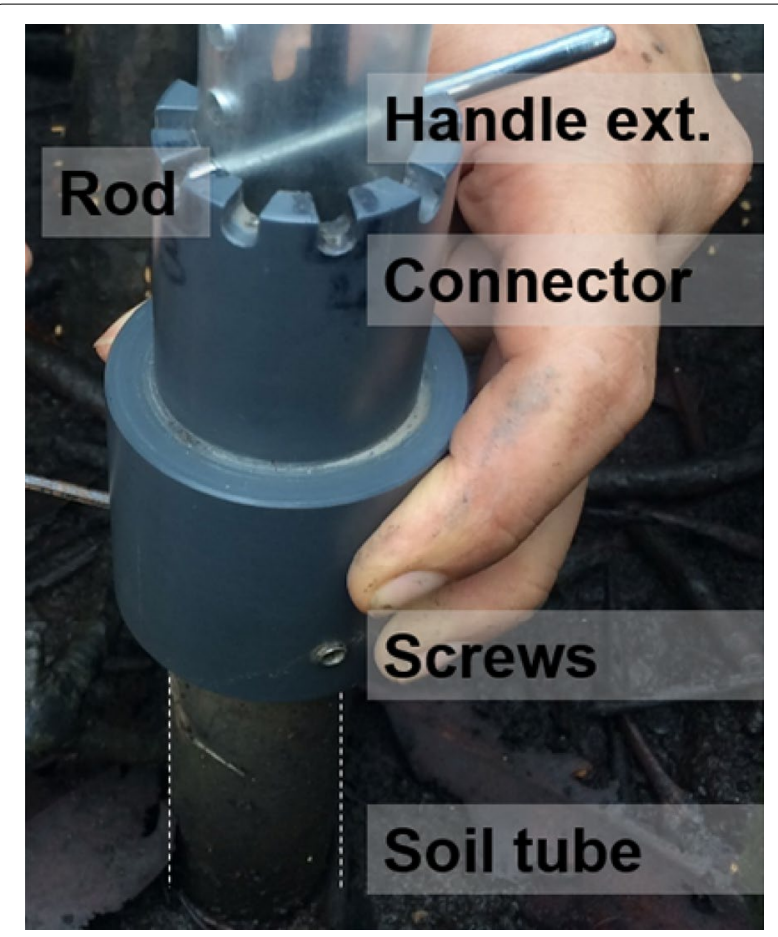

Fig. 4 EnRoot's indexing handle and soil tube connector allow images to be taken at precise depths and radial directions within the soil tube. The screws hold the connector in place

Once the minirhizotron is set up, EnRoot is connected to a computer, a tablet or a smartphone via its in-built USB cable (Fig. 2). No extra source of power is required. Roots are observed in real-time on the monitor's screen and saved with an image-acquisition program. We used the Smart Camera software, which is the software provided with the endoscope camera, but any image-acquisition software can operate the camera (e.g. digiCamControl, simpleCV or VideoCapture). The collected images are corrected using a geometric transformation to compensate for distortion from the cylindrical soil tube and the camera lens; correction is automated using the EnRoot bash script that we developed and have made freely available (Additional file 1, Fig. 5). EnRoot's bash script uses GDAL [2] and a Python script (included in the repository). A step by step guide to install GDAL and a guide to use the bash script is provided in Additional file 1. The images are then cropped. We recommend using the bash mode of GIMP (http://www.gimp.org) to crop the images $(<1 \mathrm{~s}$ per image). Generally, only every other image is analysed to reduce analysis time (Fig. 5, [7]). Subsampling images from different depths of a minirhizotron tube showed to have little effect on the experimental results provided the numbers of minirhizotron tubes used are sufficient $[5,7]$. If the subsampling method is used, the

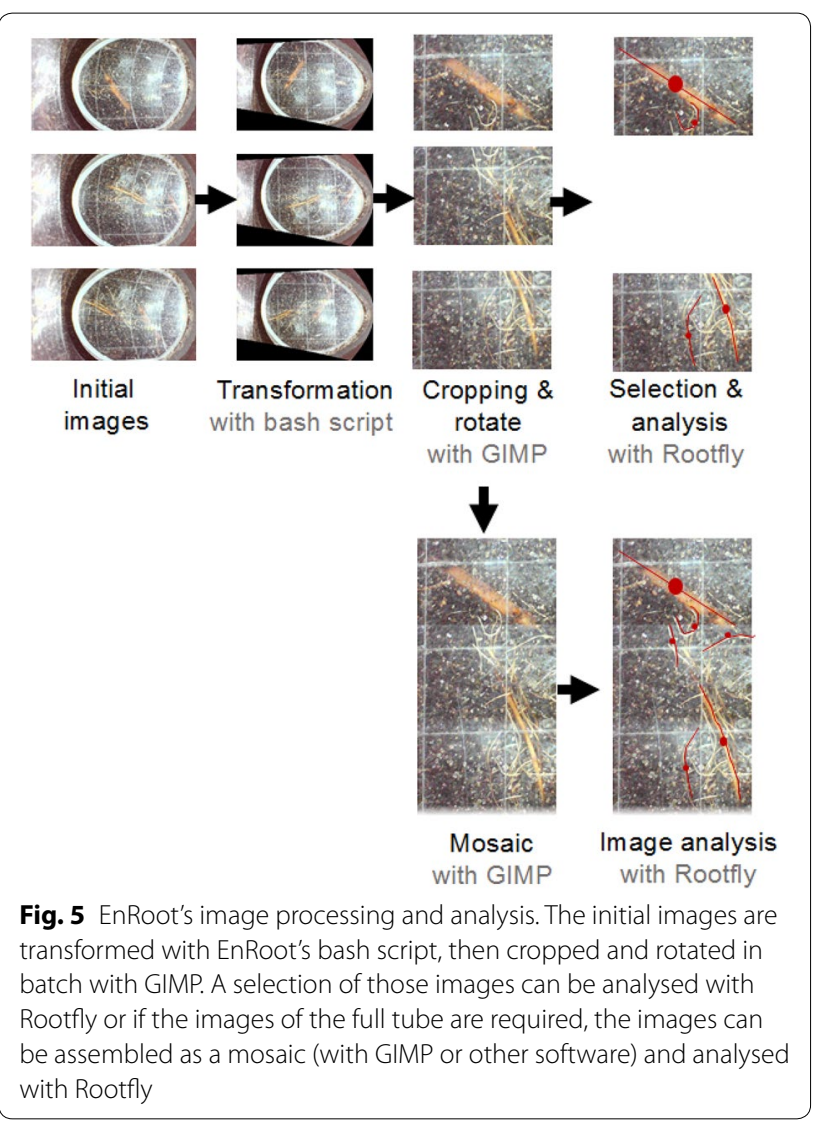

selected images can be readily analysed using any rootanalysis software (e.g. Rootfly, WinRHIZO, rhizoTrak or SmartRoot). However, if the user requires a mosaic of images covering the full soil tube, we recommend using software to create panoramas, such as GIMP, Image Composite Editor (Microsoft) or PowerPoint (Microsoft)."

\section{Testing EnRoot's performance}

The resolution of EnRoot exceeds requirements for imaging tree roots and is adequate for small roots, such as grass roots. Its maximum resolution is $1600 \times 1200$ pixels, equivalent to $28 \mu \mathrm{m}$ per pixel in our setup. Since two pixels are required to identify a root, EnRoot can theoretically detect roots with a minimum size of $56 \mu \mathrm{m}$. The camera can also be set to a lower resolution to save disk space, for example at $1280 \times 720$ pixels, allowing for roots of a minimum size of $74 \mu \mathrm{m}$ to be imaged.

We developed EnRoot with the aim that anyone can reproduce it easily. The assembly of EnRoot does not require prior training and takes less than an hour. Its components-the connectors, adaptor and two camera-apparatus supports-are 3D printable. The 3D files 
required to fabricate these are freely available for use and modification (Additional file 2). We printed these components in polylactic acid thermoplastic using the 3D Hubs printing platform (https://www.3dhubs.com). We chose this platform because of its low price and because it is available in 140 countries, making EnRoot reproducible almost everywhere.

\section{EnRoot's accuracy and precision}

The measurements of fine root production using minirhizotrons are made by extracting the diameter and length of roots from a series of root images. In order to test EnRoot's accuracy and precision, we compared root lengths and diameters obtained with EnRoot with measurements from a high-resolution flat scanner (see "Methods"). The root diameters and lengths obtained using EnRoot and the high-resolution scanner were very similar, producing concordance correlation coefficients of 0.95 for root diameter and 0.92 for root length (Lin's Concordance Correlation Coefficient, Fig. 6). Depending on the descriptive scale used, these values of concordance can be described as moderate to excellent $[1,11]$. Despite these encouraging results, there are differences in measurements between the methods (Fig. 6), which we suspect are mainly due to (i) the semi-manual method used by Rootfly to trace and extract root lengths and diameters, and (ii) some alteration of the roots during their attachment to the tube and their installation in the test pot (see "Methods").

\section{Using EnRoot in mesocosms and in situ}

We used a series of mesocosm experiments, and installed EnRoot soil tubes in mangroves (see "Methods"), to test the system's practicality and capacity to image complex rooting systems under different environmental conditions. From the images captured with EnRoot we determined the lengths, diameters, total area and total biomass of the roots in each mesocosm (Table 1). The high resolution, low glare and full colour of the images made it easy to distinguish roots from the substrate (Fig. 7) and delineate root length and diameter using Rootfly (Fig. 7). Specular reflection of the light from the LEDs against the soil tube caused some glare but did not impede the detection and measurement of roots. The initial distortion of the pictures was properly corrected with EnRoot's bash script.

EnRoot was practical and easy to use. The movement of the imaging module through the soil tube was easily controllable with the indexing handle. It was possible to stop the minirhizotron movement with the help of the connector at any time to capture high resolution images (Fig. 7). The soil tubes remained sealed with no water ingress, and the images were acquired almost instantaneously.

In the field, EnRoot soil tubes could easily be installed in-between the aerial and belowground roots of mangroves (a tropical forested wetland, Fig. 8). After 4 months of installation, the roots had developed around the minirhizotron soil tube and were clearly visible in

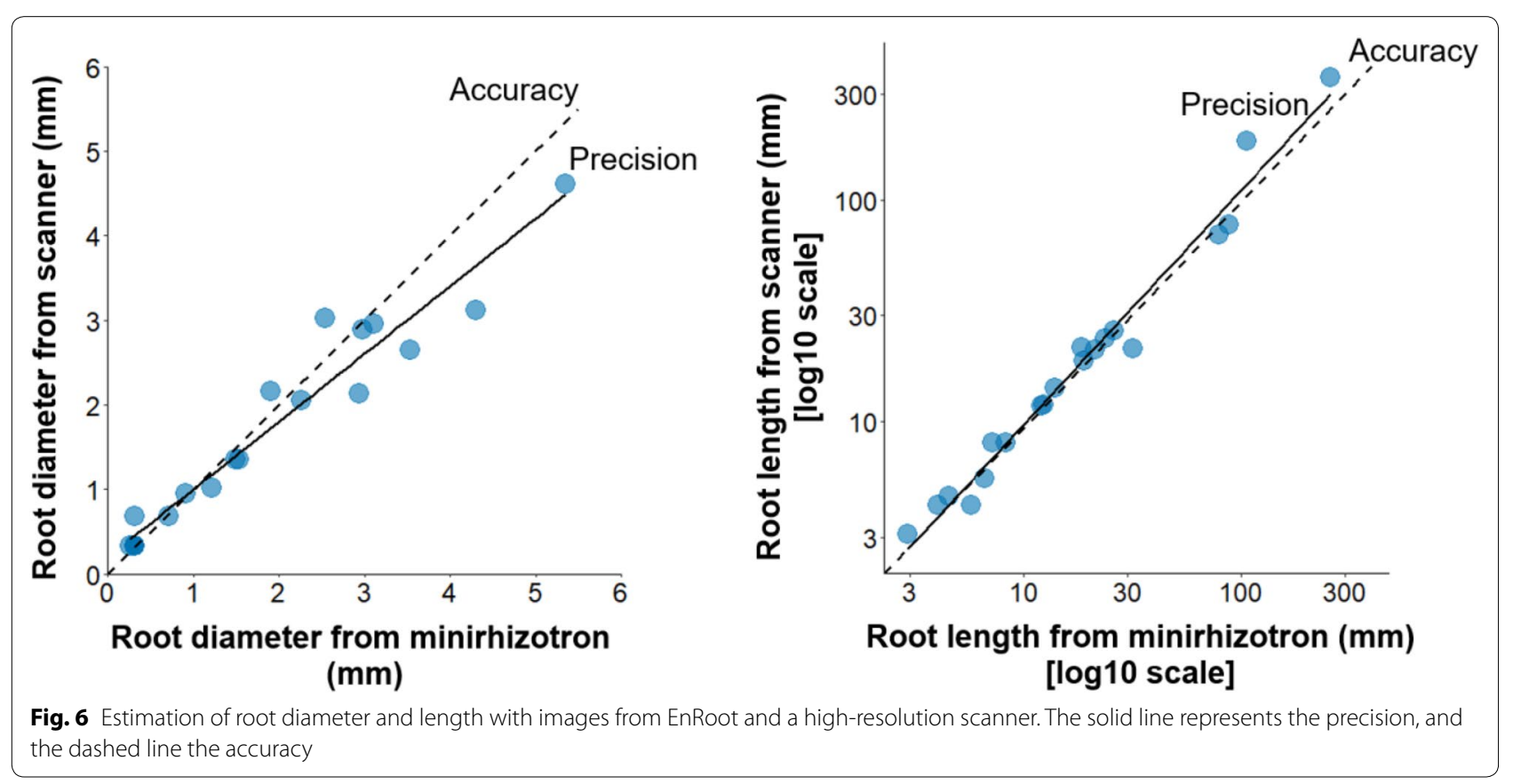


Table 1 Maximum root length and diameter recorded within each mesocosm with the accumulated area of roots imaged with EnRoot and the associated estimated biomass

\begin{tabular}{|c|c|c|c|c|c|c|c|c|c|c|}
\hline & \multicolumn{10}{|c|}{ Mesocosm } \\
\hline & 1 & 2 & 3 & 4 & 5 & 6 & 7 & 8 & 9 & 10 \\
\hline \multicolumn{11}{|l|}{ Rhizophora mangle } \\
\hline Maximum root length (mm) & 20.6 & 35.5 & 20.3 & 39 & 23.8 & 32.3 & 36.4 & 23.5 & 24.6 & 42.8 \\
\hline Maximum root diameter (mm) & 1.3 & 1.9 & 1 & 2.4 & 1.3 & 3 & 2.0 & 2.3 & 2.0 & 2.2 \\
\hline Total area $\left(\mathrm{mm}^{2}\right)$ & 70 & 77.19 & 75.6 & 93.11 & 102.5 & 122.62 & 154.52 & 190.07 & 194 & 244.5 \\
\hline Biomass (g wet weight) & 0.10 & 0.11 & 0.11 & 0.13 & 0.14 & 0.17 & 0.22 & 0.27 & 0.27 & 0.34 \\
\hline \multicolumn{11}{|l|}{ Medicago sativa } \\
\hline Maximum root length (mm) & 40.22 & 42.65 & 41.34 & 36.01 & 86.33 & 95.39 & & & & \\
\hline Maximum root diameter (mm) & 1.20 & 0.76 & 1.17 & 1.23 & 1.40 & 0.99 & & & & \\
\hline Total area $\left(\mathrm{mm}^{2}\right)$ & 48.46 & 50.50 & 59.83 & 100.59 & 219.17 & 227.38 & & & & \\
\hline
\end{tabular}
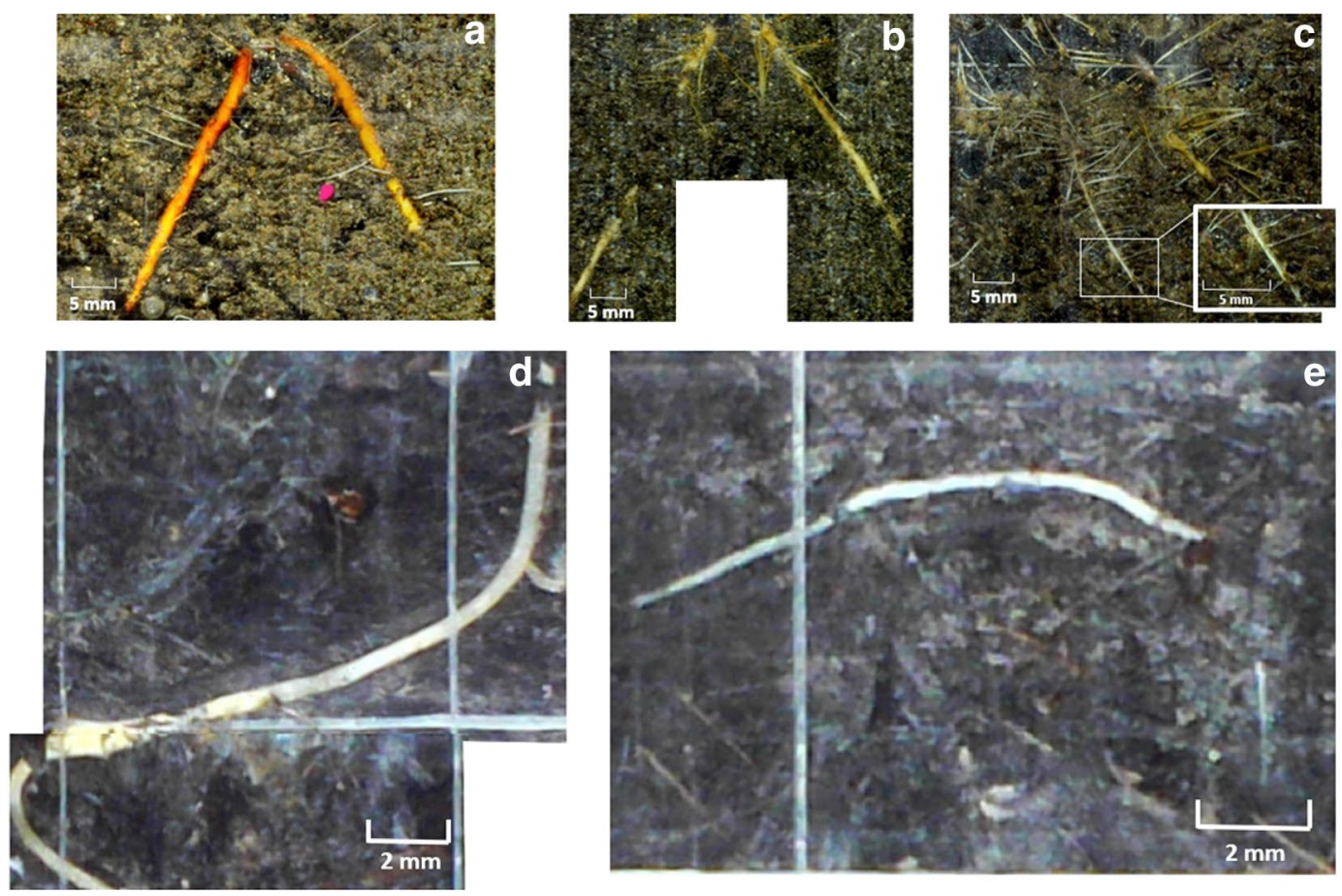

Fig. 7 Images of Rhizophora mangle roots with a magnified root in the white box (a-c) and Medicago sativa roots (d, e) using EnRoot

the video we recorded (Additional file 3). There was no water ingress in 59 EnRoot soil tubes after 10 months of installation. Only one tube, that was unknowingly damaged prior to installation, had water ingress. The EnRoot imaging module was accidentally inserted while water was within this soil tube, but it did not cause any damage because the camera is waterproof. The tops of the soil tubes were closed in the field sites with a rubber bung sealed with aquarium sealant. This prevented water ingress from tidal water.

\section{Comparison of EnRoot specifications with other systems}

EnRoot has similar or better specifications than commercial minirhizotrons (see Table 2). The resolution of the images 


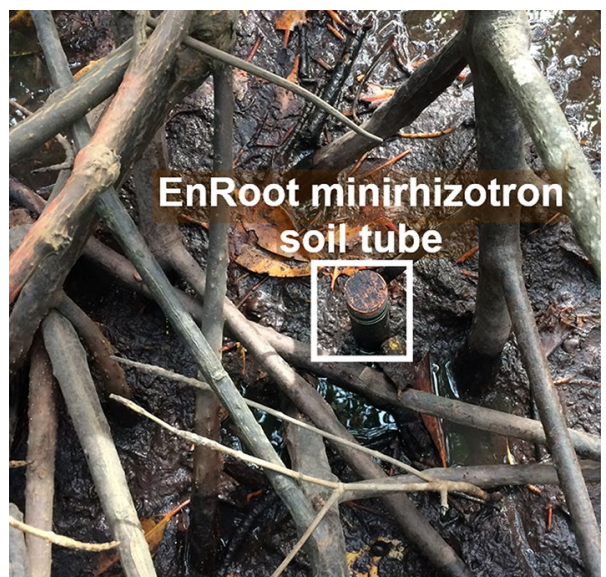

Fig. 8 An EnRoot soil tube installed between stilt roots of mangrove trees in Vietnam

is comparable to other minirhizotrons, but EnRoot is much cheaper than commercial minirhizotrons, at approximately one hundredth to one sixtieth of their price. EnRoot is not, however, suitable for studying hyphae and mycorrhizae. Use of a higher-resolution camera has the potential to extend the system's capacity to studying such smaller features, albeit at an increased cost. The capture times and the size of the images captured with EnRoot was similar to or better than commercial minirhizotrons. The advantages of EnRoot over commercial minirhizotrons are its: low weight, waterproof camera, small diameter and that it does not require an additional energy source because the system is powered by the computer, tablet or smartphone that it is connected to. EnRoot is also more flexible than commercial minirhizotrons, because it can be easily and freely adapted to different soil tube sizes and image-acquisition software (e.g. digiCamControl, simpleCV or VideoCapture).

\section{Conclusion}

EnRoot opens the minirhizotron method to (i) new usage, particularly in large scale, distributed sampling schemes; (ii) new users, such as researchers in low income countries or those with limited equipment budgets; and (iii) new, carbon-rich ecosystems, such as tropical forested wetlands. The small diameter and waterproofness of EnRoot increases the range of application of minirhizotrons without compromising the quality of the image; EnRoot's resolution allows theoretical identification of roots with diameters of $56 \mu \mathrm{m}$ and greater. EnRoot's lightweight, small diameter tube and no need for external battery offer extra advantages in remote sites. The components of EnRoot are also highly customisable and replacements can be easily built or bought, or 3D printed at low cost.

EnRoot could potentially be enhanced if operated with an external computer program, such as OpenCVPython, or with rhizoTrak (e.g., for image cropping, creating a mosaic of images and image analysis). Recent progress in the automatic detection and measurement of objects with computer programs means that it is likely that, in the future, the root images could be analysed automatically in order to extract root length, diameter and area directly in the field. Some programs have already been developed in this direction and could be used with EnRoot (e.g., SegRoot or the multiple instance learning algorithms). Such an improvement would save processing image time in the laboratory and remove the lag between image collection and the obtaining of root production data.

Because EnRoot is cheap to build, freely reproducible and easy to use, it has the potential to close our knowledge gap regarding fine root production. Finally, we have focused primarily on root production

Table 2 Comparison of EnRoot with the commercial minirhizotrons most cited in the literature

\begin{tabular}{|c|c|c|c|c|}
\hline \multirow[t]{2}{*}{ Characteristics } & \multicolumn{4}{|l|}{ Minirhizotron system } \\
\hline & EnRoot (this article) & CID bioscience $\mathrm{Cl}-600$ & $\begin{array}{l}\text { Bartz technology } \\
\text { BTC-100X }\end{array}$ & $\begin{array}{l}\text { RhizoSystems }{ }^{\mathrm{TM}} \text {, LLC } \\
\text { Manual minirhizotron }\end{array}$ \\
\hline Price $(\sim €)$ & 150 & 14,500 & 17,500 & $>13,500$ \\
\hline Waterproof camera & Yes & No & No & No \\
\hline Theoretical resolution $(\mu \mathrm{m} / \mathrm{pixels})^{\mathrm{a}}$ & 28 & 42 & 25 & 13 \\
\hline Image size $(\mathrm{mm})$ & $17 \times 12$ & $216 \times 196$ & $13.5 \times 18$ & $8.4 \times 6.3$ \\
\hline Capture time (s) & 0 to 3 & 30 to $480^{b}$ & Not indicated & Not indicated \\
\hline Weight (imaging system only) (g) & 250 & 750 & 450 & 6800 \\
\hline Size $(\mathrm{mm})$ & $\begin{array}{l}\text { Diameter: }>25 \\
\text { Length: all possible }\end{array}$ & $\begin{array}{l}\text { Diameter: } 63.5 \\
\text { Length: } 1830\end{array}$ & $\begin{array}{l}\text { Diameter: } 51 \\
\text { Length: } 1820\end{array}$ & $\begin{array}{l}\text { Diameter: } 50 \\
\text { Length: } 2000\end{array}$ \\
\hline Battery life (h) & No battery needed & $>4$ & 8 & 11 \\
\hline Magnifier & No & No & Yes & Yes \\
\hline
\end{tabular}

\footnotetext{
a Theoretical resolution was calculated by dividing the size of the picture by the maximum resolution

b For scanning an image of $21.6 \times 19.6 \mathrm{~cm}$
} 
measurements, but EnRoot could also be used for other applications, such as root phenology studies.

\section{Methods \\ Evaluation of EnRoot for accuracy and precision}

To test EnRoot's accuracy and precision, we used a high-resolution flat scanner $(2400 \times 4800 \mathrm{dpi}$, Expression 11000XL, Epson) to scan 20 roots of Red mangrove (Rhizophora mangle) with a range of diameters and lengths. The same roots were then wrapped with a transparent plastic film around an EnRoot soil tube $(32 \mathrm{~mm}$ diameter, $50 \mathrm{~cm}$ long) subsequently placed in a test pot $(60 \mathrm{~cm}$ long and $110 \mathrm{~mm}$ diameter, for a total volume of $5702 \mathrm{~cm}^{3}$ ) filled with a peaty soil and then saturated with water. EnRoot was then used to image the same 20 roots. The length and the diameter of the roots were extracted using the freely available software Rootfly [14]. We used Lin's Concordance Correlation Coefficient to compare the output from both instruments [8]. This metric incorporates both accuracy and precision to quantify the level of agreement between paired measurements and is commonly used to assess bias between instruments or human operators. Accuracy is incorporated through a bias correction factor that represents the gradient of the best-fit line compared to the 1:1 line; while precision is incorporated through the use of Pearson's Correlation Coefficient (Fig. 6). The value of Lin's Concordance Coefficient increases towards one as the compared data approach perfect agreement.

\section{EnRoot trial}

The mesocosm experiment was undertaken for 6 months to generate a range of root lengths and diameters representing different stages of fine root production. In the first batch of mesocosms, we mimicked field conditions of mangrove forests. In a greenhouse, 10 Rhizophora mangle propagules were planted in ten mesocosm pots $(60 \mathrm{~cm}$ long and $110 \mathrm{~mm}$ diameter, for a total volume of $5702 \mathrm{~cm}^{3}$ ) filled with a mix of sandy and peaty substrate, which was periodically saturated with water. The temperature was maintained at $26{ }^{\circ} \mathrm{C}$ with a relative air humidity of $70 \%$. In each mesocosm, an EnRoot soil tube (32 $\mathrm{mm}$ diameter and $50 \mathrm{~cm}$ long) was installed. After the saplings exhibited first leaf out, we used EnRoot to image the roots of one mesocosm per day at 10 random dates over 6 months. We imaged only the area with roots. We repeated the same experiment with an Alfalfa crop (Medicago sativa) in six mesocosms of a peat-only substrate, with temperature maintained between 24 and $26{ }^{\circ} \mathrm{C}$ and an average relative air humidity of $30 \%$. Each set of root images was corrected for distortion using EnRoot's bash script. The images were then cropped using GIMP (http://www.gimp.org) and assembled as a mosaic with GIMP and PowerPoint (Microsoft). The length and diameter of roots within each mesocosm were extracted from mosaics of images using Rootfly. In each mesocosm we identified the longest root and the thickest root, as well as the cumulative area of all the roots imaged. The longest root was defined by the longest continuous segment of root visible. We estimated the fine root biomass of each mangrove mesocosm. Root wet biomass was calculated with a simplified area:biomass coefficient that we calculated for the Rhizophora mangle roots. The installation of EnRoot soil tubes was tested in three mangrove sites in the Can Gio Biosphere Reserve in the Mekong Delta in Vietnam where we installed 60 EnRoot soil tubes at $1 \mathrm{~m}$ depth. We generated 60 random locations and installed at each an EnRoot soil tube $(1.2 \mathrm{~m}$ long, so $0.2 \mathrm{~m} \mathrm{left}$ above the ground surface) using a screw auger of $31 \mathrm{~mm}$ diameter. We changed the initial location of three tubes, because we could not core due a very hard substrateprobably large belowground roots. All of the tubes were installed vertically in the soil $\left(90^{\circ}\right)$.

\section{Comparing EnRoot with commercial minirhizotrons}

EnRoot was compared with 3 other commercial minirhizotrons in terms of nine characteristics that we deemed to be important, such as camera resolution, weight and price (see Table 2 for full list). Details of the commercially-available minirhizotrons were provided by suppliers, manufacturers' online documentation, and peer-reviewed publications.

\section{Supplementary information}

Supplementary information accompanies this paper at https://doi. org/10.1186/s13007-019-0489-6.

Additional file 1. Bash script to correct image distortion with a how-touse guide and Fig. S2.1.

Additional file 2. 3D files for printing the components of EnRoot with a quick guide.

Additional file 3. Video of mangrove roots development recorded with EnRoot imaging device.

\section{Acknowledgements}

Development of the prototype system received support from Antony Windross, from the School of Earth and Environment's workshop at the University of Leeds. The 3D pictures and files were made using the 3D hub supplier

Gateros Plating and were further modified by Johan Fruh. David Ashley helped assemble the mesocosms. Rakesh Tiwari took the picture of the device (Fig. 1).

\section{Authors' contributions}

MA led the development of the EnRoot minirhizotron and the laboratory tests, and wrote the manuscript. AJB and PJM contributed to the design of EnRoot and the laboratory tests, as well as to the writing of the manuscript. JH and $\mathrm{AH}$ developed the image correction technique. All authors contributed critically to manuscript development. All authors read and approved the final manuscript. 


\section{Funding}

The costs of the materials and the experiment were supported by a Leeds University Anniversary Research Scholarship, and a water@Leeds Grant, both awarded to MA.

\section{Availability of data and materials}

The material and dataset supporting the conclusions of this article are included within the article and its additional files.

\section{Ethics approval and consent to participate}

Not applicable.

\section{Consent for publication}

Not applicable.

\section{Competing interests}

The authors declare that they have no competing interests.

\section{Author details}

${ }^{1}$ School of Geography, University of Leeds, Leeds LS2 9JT, UK. ${ }^{2}$ School of Environment and Development, University of Manchester, Manchester M13 9PL, UK.

Received: 15 May 2019 Accepted: 21 August 2019

Published online: 28 August 2019

\section{References}

1. Altman DG. Practical statistics for medical research. London: Chapman \& Hall; 1991. p. 285-8. https://doi.org/10.1002/sim.4780101015.

2. GDAL contributors. GDAL Geospatial Data Abstraction software Library. Open Source Geospatial Foundation. 2019. https://gdal.org. Accessed 11 June 2019

3. Hendricks JJ, Hendrick R, Wilson CA, Mitchell RJ, Pecot SD, Guo D. Assessing the patterns and controls of fine root dynamics: an empirical test and methodological review. J Ecol. 2006;94(1):40-57. https://doi.org/10.111 1/j.1365-2745.2005.01067.x.
4. Hendrick RL, Pregitzer KS. Applications of minirhizotrons to understand root function in forests and other natural ecosystems. Plant Soil. 1996;185:291-302. https://doi.org/10.1007/BF02257535.

5. Iversen CM, Murphy MT, Allen MF, et al. Advancing the use of minirhizotrons in wetlands. Plant Soil. 2011;352(1-2):23-39. https://doi. org/10.1007/s11104-011-0953-1.

6. Jackson RB, Mooney HA, Schulze ED. A global budget for fine root biomass, surface area, and nutrient contents. Proc Natl Acad Sci USA. 1997:94:7362-6. https://doi.org/10.1073/pnas.94.14.7362.

7. Johnson MG, Tingey DT, Phillips DL, Storm MJ. Advancing fine root research with minirhizotrons. Environ Exp Bot. 2001;45(3):263-89. https:// doi.org/10.1016/s0098-8472(01)00077-6.

8. Lin LI. A concordance correlation coefficient to evaluate reproducibility. Biometrics. 1989;45:255-68. https://doi.org/10.2307/2532051.

9. Majdi H. Root sampling methods - applications and limitations of the minirhizotron technique. Plant Soil. 1996;185(2):255-8. https://doi. org/10.1007/Bf02257530.

10. Marthews TR, Riutta T, Oliveras Menor I, et al. Measuring tropical forest carbon allocation and cycling: a RAINFOR-GEM field manual for intensive census plots (v3.0). Manual, Global Ecosystems Monitoring network. 2014. http://gem.tropicalforests.ox.ac.uk/. Accessed 11 June 2019

11. McBride GB. A proposal for strength-of-agreement criteria for Lin's concordance. NIWA Client Report: HAM2005-062. 2005.

12. Mohamed A, Monnier Y, Mao Z, Lobet G, Maeght JL, Ramel M, Stokes A. An evaluation of inexpensive methods for root image acquisition when using rhizotrons. Plant Methods. 2017;13:11. https://doi.org/10.1186/ s13007-017-0160-z.

13. Vogt KA, Vogt DJ, Bloomfield J. Analysis of some direct and indirect methods for estimating root biomass and production of forests at an ecosystem level. Plant Soil. 1998;200:71-89. https://doi.org/10.1023/A:1004313515294.

14. Zeng G, Birchfield ST, Wells CE. Automated discrimination of fine roots in minirhizotron images. New Phytol. 2008;177:549-57. https://doi.org/10.1 111/j.1469-8137.2007.02271.x.

\section{Publisher's Note}

Springer Nature remains neutral with regard to jurisdictional claims in published maps and institutional affiliations.
Ready to submit your research? Choose BMC and benefit from:

- fast, convenient online submission

- thorough peer review by experienced researchers in your field

- rapid publication on acceptance

- support for research data, including large and complex data types

- gold Open Access which fosters wider collaboration and increased citations

- maximum visibility for your research: over $100 \mathrm{M}$ website views per year

At BMC, research is always in progress.

Learn more biomedcentral.com/submissions 